\title{
The Prevalence and Correlates of Eating Between Meals in a Cross-Sectional Study of a Health Oriented Adult Population
}

\begin{abstract}
Nadasan Valentin*, Gabos Gabriella, Tarcea Monica, Abram Zoltan
University of Medicine and Pharmacy Tirgu Mureș, Romania

Objectives: To assess the prevalence of snacking and to explore the relationship between snacking and several demographic, anthropometric, functional and biochemical factors. Methods: The study included 756 individuals over 18 years of age from Medias, Romania. Demographics and data about snacking were collected by trained volunteers. Height, weight, waist circumference, blood pressure were measured with standard equipment according to accepted procedures. Blood glucose and cholesterol were measured by experienced nurses using portable devices. Associations between variables were checked with the Pearson Chi-square test. Odds ratios and 95\% confidence intervals were calculated to measure the association between binary variables. Results: About half of the subjects in the studied sample reported snacking less than 2 times / week, 34.5\% between 3-4 times / week and 14.8\% more than 4 times / week. Statistical analysis found that snacking was associated with gender (males being less likely to snack than females), ethnicity (non-Romanians being less likely to snack than Romanian ethnics), marital status of the subjects (not married people being less likely to snack than married people ), systolic blood pressure (people consuming more often snacks being less likely to have high systolic blood pressure values), and blood sugar level (people eating more frequently between meals being more likely to have higher blood glucose levels). Conclusions: Snacking was a widespread eating habit among the study participants and was significantly associated with gender, ethnicity, marital status, systolic blood pressure and blood glucose levels.
\end{abstract}

Keywords: eating between meals, nutrition, correlates, blood pressure, blood glucose

Received: 27 August 2015 / Accepted: 02 November 2015

\section{Introduction}

Avoiding or limiting food consumption between regular meals has been considered for almost half a century a behavioral factor that may contribute to enhanced health and increased longevity [1]. Snacking or between meal eating episodes (BMEE) seem correlated with a high caloric intake [2]. In US adult population, snacks provide $24 \%$ of the total daily calory intake and 1 out of 6 American adults are taking over $40 \%$ of their daily calories from food and beverages reported as snacks [3]. There are studies suggesting that a high consumption of sweets, snacks, spices, carbohydrates and a low vegetable intake could promote weight gain and might increase the risk of diabetes $[4,5]$. However, there is no generally accepted definition of snacks and there is no consensus about the impact of snacking on diet quality $[6,7]$.

A limited number of studies have explored the demographic and social correlates of snacking in different populations around the world [3,8-10]. Exposure to commercial advertising of snacks and the extent of watching TV programs was associated with a higher likelihood of serving fast foods and sweets, in both children and adults $[11,12]$.

Given the lack of information in this area, this study aimed: (1) to assess the prevalence of snacking as a component of eating behavior in a group of people with an increased degree of interest in health issues and (2) to

* Correspondence to: Valentin Nadasan

E-mail: valentin.nadasan@umftgm.ro explore the relationship between snacking and several demographic, anthropometric, functional and biochemical factors.

\section{Material and methods}

\section{Subjects}

The sampling frame consisted of 871 persons who participated voluntarily in a community health promotion campaign called Health-Expo, between 1-4 June 2010 in Medias, a city with an estimated population of about 50,000 inhabitants. The organizational details of the campaign were described in detail in a previously published paper [13]. The analytical sample for the study included 756 individuals over 18 years of age, who agreed to answer the questionnaire and requested the measurements offered by the organizers at the campaign location. The participation rate was $86.8 \%$.

\section{Collected / measured variables}

Demographics (age, gender, residence, educational attainment, marital status, ethnicity) and data about snacking were collected by trained volunteers. Height, weight, waist circumference, blood pressure were measured with standard equipment according to accepted procedures. Body mass index (BMI) was calculated according to the formula: BMI = weight $(\mathrm{kg}) /$ height $^{2}(\mathrm{~m})$. Blood glucose and cholesterol were measured using portable devices (Bioland G- $-423^{\mathrm{TM}}$, respectively Accutrend PLUS ${ }^{\mathrm{TM}}$ ). In both cases, 
capillary sampling was performed by experienced nurses following strict asepsis rules and the equipment manufacturer's technical instructions.

Subjects were grouped into subcategories based on reference values accepted in the literature, as follows: BMI $(<18.5$ units - underweight, between 18.5 and 24.9 units normal weight, between 25.0 and 29.9 units - overweight; $\geq 30$ units - obese) [14], abdominal circumference $(102 \mathrm{~cm}$ in men or $88 \mathrm{~cm}$ in women) [15], blood pressure $(<140$ $\mathrm{mmHg} / \geq 140 \mathrm{mmHg})$ [16], blood glucose levels $(<126$ $\mathrm{mg} / \mathrm{dL} / \geq 126 \mathrm{mg} / \mathrm{dL})$ [17], the total cholesterol $(<240$ $\mathrm{mg} / \mathrm{dL} / \geq 240 \mathrm{mg} / \mathrm{dL}$ ) [18].

\section{Statistical analysis}

Descriptive statistics were calculated by categories and subcategories for each collected variable. Associations between variables were checked with the Pearson Chi square test. Odds ratios and $95 \%$ confidence intervals were calculated to measure the association between binary variables. Statistical analyzes were performed in SPSS Base. V.22 package. The threshold value of statistical significance was set at 0.05 .

\section{Results}

The descriptive data of the current sample are presented in Table I.

The distribution of subjects according to the frequency of snacking is shown in Figure 1.

The relationship between the frequency of snacking (dichotomised: no $=$ seldom or never $/$ yes $=3-7$ days $/$ week $)$ and demographic variables is presented in Table II.

The relationship between the frequency of snacks between meals (dichotomised: no $=$ seldom or never $/$ yes $=$ 3-7 days / week) and anthropometrical, functional, biochemical characteristics are shown in Table III.

Table I. Demographic characteristics of the sample

\begin{tabular}{lcc}
\hline Variable & Categories & $\mathrm{N}(\%)$ \\
\hline \multirow{4}{*}{ Age } & $18-29$ years & $21(2.8)$ \\
& $30-39$ years & $57(7.5)$ \\
& $40-49$ years & $87(11.5)$ \\
& $50-59$ years & $157(20.8)$ \\
& $60-69$ years & $243(32.1)$ \\
Gender & $\geq 70$ years & $191(25.3)$ \\
\hline \multirow{2}{*}{ Residence } & Male & $524(69.3)$ \\
& Female & $232(30.7)$ \\
\hline \multirow{2}{*}{ Educational } & Urban & $688(91.0)$ \\
attainment & Rural & $68(9.0)$ \\
& Primary school & $96(12.7)$ \\
& Secondary school & $192(25.4)$ \\
& High school & $265(35.1)$ \\
& College & $109(14.4)$ \\
Marital status & University & $94(12.4)$ \\
& Single & $81(10.7)$ \\
& Married & $473(62.6)$ \\
& Divorced & $46(6.1)$ \\
& Widowed & $156(20.6)$ \\
\hline \multirow{3}{*}{ Ethnicity } & Romanian & $645(85.3)$ \\
& Hungarian & $95(12.6)$ \\
& Other & $16(2.1)$ \\
\hline
\end{tabular}

\section{Discussions}

The research has found that snacking was a widespread eating habit among the study participants but not as common as reported in some other countries. Almost half of the subjects in our study (49.3\%) were serving snacks on a daily basis or at least 3-4 times a week. A US study showed that between $60-70 \%$ of American children and 40-65\% of American adults serve snacks at least once a day [19]. A Brazilian study reported that $74 \%$ of the individuals over 10 years of age used to serve a snack per day, and another $23 \%$ three or more than three snacks per day [20]. However, comparison of data has to be done with caution keeping in mind the lack of generally accepted definitions and methods for snacks quantification as well as differences in sampling.

Snacking was associated with gender (males being less likely to snack than males $\mathrm{OR}=0.512$ ), ethnicity (other ethnics being less likely to snack than Romanian ethnics $\mathrm{OR}=0.577$ ) and marital status of the subjects (not married people being less likely to snack than married people $\mathrm{OR}=0.690$ ), but not with age, residence and educational attainment. While marketing research data published in popular media shows that American women are $15 \%$ more likely to snack than men, we found no scientific papers that support or reject the association of gender, ethnicity and marital status observed in our study.

More frequent snacking was associated in our study with lower systolic blood pressure. This finding is somewhat intriguing if salty snacks are taken in consideration although the link between high salt intake and hypertension is still a matter of scientific debate [21]. A plausible explanation of the inverse association found in our study could be related to the beneficial effect of healthy snacks, such as fruits, known for their high potassium content [22].

The association of frequent eating between meals and higher blood glucose values in our sample is another finding that needs further clarification since some studies suggest a beneficial effect of more frequent eating on blood sugar levels [23]. However, these studies measured glycemia in diabetic subjects trying to control their blood sugar by dietary pattern manipulation.

Our study showed no association between snacking and BMI or waist circumference. While some of the published studies suggest that regardless of the macronutrient com-

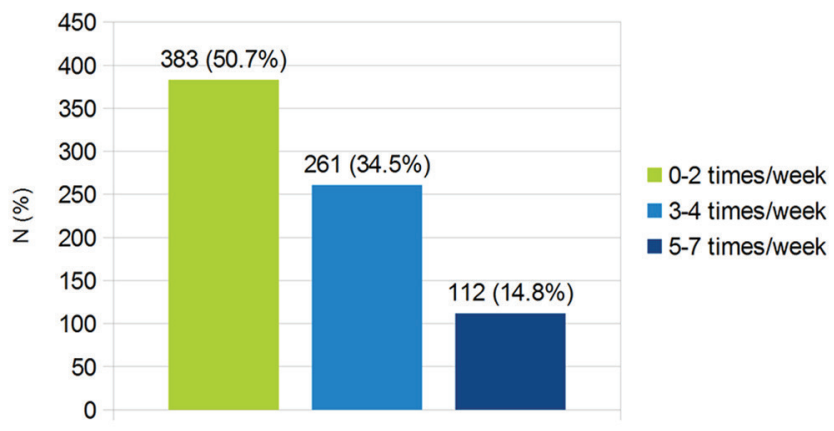

Fig. 1. Prevalence of snacking by frequency 
Table II. Analysis of the association between frequency of snacks and demographic variables

\begin{tabular}{|c|c|c|c|c|c|c|}
\hline & \multirow{3}{*}{ Variable } & \multicolumn{2}{|c|}{ Snacking } & \multirow{3}{*}{$\chi^{2}$} & \multirow{3}{*}{$\mathrm{p}$ value } & \multirow{3}{*}{$\begin{array}{c}\mathrm{OR}^{\star \star} \\
(95 \% \mathrm{Cl})^{\star \star \star}\end{array}$} \\
\hline & & No & Yes & & & \\
\hline & & $\mathrm{N}(\%)$ & N (\%) & & & \\
\hline \multirow{6}{*}{ Age } & $18-29$ years & $8(38.1)$ & $13(61.9)$ & \multirow{6}{*}{6.729} & \multirow{6}{*}{0.242} & \multirow{6}{*}{-} \\
\hline & $30-39$ years & $31(54.4)$ & $26(45.6)$ & & & \\
\hline & $40-49$ years & $41(47.1)$ & $46(52.9)$ & & & \\
\hline & $50-59$ years & $70(44.6)$ & $87(55.4)$ & & & \\
\hline & 60-69 years & $126(51.9)$ & $117(48.1)$ & & & \\
\hline & $\geq 70$ years & $107(56.0)$ & $84(44.0)$ & & & \\
\hline \multirow{2}{*}{ Gender } & Male & $144(62.1)$ & 88 (37.9) & \multirow{2}{*}{17.426} & \multirow{2}{*}{$<0.0001$} & \multirow{2}{*}{$0.512(0.374-0.703)$} \\
\hline & Female & $239(45.6)$ & $285(54.4)$ & & & \\
\hline \multirow{2}{*}{ Residence } & Urban & $348(50.6)$ & $340(49.4)$ & \multirow{2}{*}{0.020} & \multirow{2}{*}{0.889} & \multirow{2}{*}{$0.965(0.586-1.589)$} \\
\hline & Rural & $35(51.5)$ & $33(48.5)$ & & & \\
\hline \multirow{2}{*}{$\begin{array}{l}\text { Educational } \\
\text { attainment* }^{*}\end{array}$} & Under graduate studies & $337(50.9)$ & $325(49.1)$ & \multirow{2}{*}{0.128} & \multirow{2}{*}{0.721} & \multirow{2}{*}{$1.082(0.702-1.667)$} \\
\hline & Graduate studies & $46(48.9)$ & $48(51.1)$ & & & \\
\hline \multirow{2}{*}{ Ethnicity * } & Romanian & $314(48.7)$ & $331(51.3)$ & \multirow{2}{*}{6.885} & \multirow{2}{*}{0.009} & \multirow{2}{*}{$0.577(0.382-0.873)$} \\
\hline & Other & $69(62.2)$ & $42(37.8)$ & & & \\
\hline \multirow{2}{*}{ Marital status* } & Married & $127(44.9)$ & $156(55.1)$ & \multirow{2}{*}{6.056} & \multirow{2}{*}{0.014} & \multirow{2}{*}{$0.690(0.513-0.928)$} \\
\hline & Other & $256(54.1)$ & 217 (45.9) & & & \\
\hline
\end{tabular}

* The original subcategories were merged in order to meet the conditions required by the statistical test; ** OR = Odds Ratio; $95 \% \mathrm{Cl}=95 \%$ Confidence interval

Table III. Analysis of the association between frequency of snacks and the anthropometrical, functional, and biochemical variables

\begin{tabular}{|c|c|c|c|c|c|c|}
\hline & \multirow{3}{*}{ Variable } & \multicolumn{2}{|c|}{ Snacking } & \multirow{3}{*}{$\chi^{2}$} & \multirow{3}{*}{$p$ value } & \multirow{3}{*}{$\mathrm{OR}^{\star \star}(95 \% \mathrm{Cl})^{\star \star \star}$} \\
\hline & & No & Yes & & & \\
\hline \multirow{3}{*}{$\mathrm{BMI}^{\star}$} & & & & & & \\
\hline & $<24,99$ & $76(46.9)$ & $86(53.1)$ & \multirow{2}{*}{1.159} & \multirow{2}{*}{0.282} & \multirow{2}{*}{$0.826(0.583-1.170)$} \\
\hline & $\geq 25$ & $307(51.7)$ & $287(48.3)$ & & & \\
\hline \multirow{2}{*}{$\begin{array}{l}\text { Waist } \\
\text { circumference }\end{array}$} & $\begin{array}{l}\text { Males }<102 \mathrm{~cm} \\
\text { Females }<88 \mathrm{~cm}\end{array}$ & $102(53.1)$ & $90(46.9)$ & \multirow[b]{2}{*}{0.625} & \multirow[b]{2}{*}{0.429} & \multirow[b]{2}{*}{$1.141(0.822-1.584)$} \\
\hline & $\begin{array}{l}\text { Males } \geq 102 \mathrm{~cm} \\
\text { Females } \geq 88 \mathrm{~cm}\end{array}$ & $281(49.8)$ & $283(50.2)$ & & & \\
\hline \multirow{2}{*}{$\mathrm{SBP}^{*}$} & $<140 \mathrm{mmHg}$ & $192(46.7)$ & 219 (53.3) & \multirow{2}{*}{5.611} & \multirow{2}{*}{0.018} & \multirow{2}{*}{$0.707(0.530-0.942)$} \\
\hline & $\geq 140 \mathrm{mmHg}$ & $191(55.4)$ & $154(44.6)$ & & & \\
\hline \multirow[t]{2}{*}{$\mathrm{DBP}^{*}$} & $<90 \mathrm{mmHg}$ & $226(48.4)$ & $241(51.6)$ & \multirow{2}{*}{2.513} & \multirow{2}{*}{0.113} & \multirow{2}{*}{$0.788(0.588-1.058)$} \\
\hline & $\geq 90 \mathrm{mmHg}$ & $157(54.3)$ & $132(45.7)$ & & & \\
\hline \multirow{2}{*}{ Blood glucose ${ }^{*}$} & $<126 \mathrm{mg} / \mathrm{dL}$ & $349(51.9)$ & $323(48.1)$ & \multirow{2}{*}{3.922} & \multirow{2}{*}{0.048} & \multirow{2}{*}{$1.589(1.002-2.520)$} \\
\hline & $\geq 126 \mathrm{mg} / \mathrm{dL}$ & $34(40.5)$ & $50(59.5)$ & & & \\
\hline \multirow{2}{*}{ Total cholesterol* } & $<200$ mg/dL & $124(55.6)$ & $99(44.4)$ & \multirow{2}{*}{3.011} & \multirow{2}{*}{0.083} & \multirow{2}{*}{$1.320(0.964-1.808)$} \\
\hline & $\geq 200 \mathrm{mg} / \mathrm{dL}$ & $259(48.7)$ & $273(51.3)$ & & & \\
\hline
\end{tabular}

BMI: body mass index; SBP: systolic blood pressure; DBP: diastolic blood pressure; * The original subcategories were merged in order to meet the conditions required by the statistical test; ** OR = Odds Ratio; $95 \% \mathrm{Cl}=95 \%$ Confidence interval

position of the snacks, eating between meals can lead to overeating and thus obesity [24,25], other data suggest no relationship or negative relationship between snacking and overweight [26].

A first limitation of this study is the non-random selection of the subjects which limits the external validity of the observations. Compared to the general population, the study sample had a relatively high proportion of women (the woman to man ratio was over 2 to 1 ) and elderly (almost $50 \%$ of the subjects were over 50 years old). These particularities of the participants to Health-Expo campaigns were observed at other similar events organized in several cities of Romania [13,27]. These disproportionalities are very likely a result of self-selection and might be attributed to a heightened interest of women and the elderly toward their health status [28-30]. Supposedly, other factors specific to the elderly, such as the availability of free time and a stronger need for socialization might explain their overrepresentation in the studied sample.

The second limitation has to do with the accuracy of the responses. Hearing impairment and modest literacy level of some of the senior subjects might have impeded the precision of the answers given to the operators. Furthermore, in as much as snacking was perceived by respondents as a bad and shameful dietary habit, a systematic distortion of the answers - due to the phenomenon of social desirability bias - can not be excluded [31]. Finally, the discriminative power of the study was probably limited by the fact that the survey questions addressed only the frequency of snack consumption without specifying the types of food that qualify as snacks.

In spite of these limitations, the results of this study expand our knowledge about the habit of snacking and eating behavior in general. The data about snacking prevalence and correlates of snacking revealed in the study can help the organizers of community health promotion activities to tailor nutrition education messages more closely to the needs of the target population.

Replicating the investigation on a representative sample and the inclusion of more questions about the types of foods consumed as snacks could improve the accuracy and the value of the study. 


\section{Conclusions}

While half of the subjects in the studied sample reported that they never or almost never use snacks, one-third of the subjects reported snacking 3-4 times a week and 15\% daily or almost daily.

Snacking was significantly associated in our sample with the gender, ethnicity and marital status of the subjects and also with their systolic blood pressure and blood glucose levels.

\section{References}

1. Belloc NB. Relationship of health practices and mortality. Prev Med. 1973;2(1):67-81.

2. Duffey KJ, Pereira RA, Popkin BM. Prevalence and energy intake from snacking in Brazil: analysis of the first nationwide individual survey. Eur $\mathrm{J}$ Clin Nutr. 2013;67(8):868-874.

3. U.S. Department of Agriculture. What We Eat in America, NHANES, 2001-2002. Available online at: www.ars.usda.gov/SP2UserFiles/ Place/12355000/pdf/Table_5_BIA.pdf. Accesed: 08.05.2014.

4. McCrory MA, Fuss PJ, McCallum JE, et al. Dietary variety within food groups: association with energy intake and body fatness in men and women. Am J Clin Nutr. 1999;69(3):440-447.

5. Mekary RA, Giovannucci E, Cahill L, et al. Eating patterns and type 2 diabetes risk in older women: breakfast consumption and eating frequency. Am J Clin Nutr. 2013;98(2):436-443.

6. Zizza CA. Healthy snacking recommendations: One size does not fit all. Physiol Behav. 2014; pii:S0031-9384(14)00051-1.

7. Johnson $\mathrm{GH}$, Anderson GH. Snacking definitions: impact on interpretation of the literature and dietary recommendations. Crit Rev Food Sci Nutr. 2010;50(9):848-871.

8. Schoenborn CA. Health habits of U.S. adults, 1985: the "Alameda 7" revisited. Public Health Rep. 1986;101(6):571-580.

9. Saldiva SR, Venancio SI, de Santana AC, et al. The consumption of unhealthy foods by Brazilian children is influenced by their mother's educational level. Nutr J. 2014;13:33.

10. Wichaidit W, Sangthong R, Chongsuvivatwong V, et al. Religious affiliation and disparities in risk of non-communicable diseases and health behaviours: findings from the fourth Thai National Health Examination Survey. Glob Public Health. 2014;9(4):426-435.

11. Scully M, Wakefield M, Niven $P$, et al. Association between food marketing exposure and adolescents' food choices and eating behaviors. Appetite. 2012;58(1):1-5.

12. Scully $M$, Dixon $H$, Wakefield $M$. Association between commercial television exposure and fast-food consumption among adults. Public Health Nutr. 2009;12(1):105-110.

13. Nădășan V, Șular F, Horvath A, Tarcea M, Abram Z. Demographic Differences Between the Recipients of a Health Promotion Campaign and the General Population. Revista de Igienă și Sănătate Publică. 2012;62(4):31-42.

14. World Health Organization, Regional Office for Europe. Body mass index - BMI. Available online: www.euro.who.int/en/health-topics/diseaseprevention/nutrition/a-healthy-lifestyle/body-mass-index-bmi Accesed: 07.18.2014.
15. Alberti KG, Eckel RH, Grundy SM, et al. Harmonizing the metabolic syndrome: a joint interim statement of the International Diabetes Federation Task Force on Epidemiology and Prevention. Circulation. 2009;120(16):1640-1645.

16. Perk J, De Backer G, Gohlke H, et al. European guidelines on cardiovascular disease prevention in clinical practice (version 2012): the fifth joint task force of the European society of cardiology and other societies on cardiovascular disease prevention in clinical practice. Int J Behav Med. 2012;19(4):403-488.

17. American Diabetes Association. Diagnosis and classification of diabetes mellitus. Diabetes Care. 2014;37(Suppl 1):S81-90.

18. Third Report of the National Cholesterol Education Program (NCEP). Expert Panel on Detection, Evaluation, and Treatment of High Blood Cholesterol in Adults (Adult Treatment Panel III). Executive Summary. National Cholesterol Education Program, National Heart, Lung, and Blood Institute, National Institutes of Health. NIH Publication No. 01-3670 May 2001

19. National Research Council, Food and Nutrition Board. What Is America Eating?: Proceedings of a Symposium. Washington (DC), National Academies Press, 1986 p. 92. Available online at: www.ncbi.nlm.nih.gov/ books/NBK217512/ Accessed: 08.04.2014.

20. Duffey KJ, Pereira RA, Popkin BM. Prevalence and energy intake from snacking in Brazil: analysis of the first nationwide individual survey. Eur $\mathrm{J}$ Clin Nutr. 2013;67(8):868-874.

21. Burnier B, Wuerzner G, Bochud M. Salt, blood pressure and cardiovascular risk: what is the most adequate preventive strategy? A Swiss perspective. Front Physiol. 2015;6:227.

22. Weaver CM. Potassium and health. Adv Nutr. 2013;4(3):368S-77S.

23. Jenkins DJA. Carbohydrate tolerance and food frequency. British Journal of Nutrition. 1997;77(Suppl 1):S71-81.

24. McCrory MA, Campbell WW. Effects of eating frequency, snacking, and breakfast skipping on energy regulation: symposium overview. J Nutr. 2011;141(1):144-147.

25. Bes-Rastrollo M, Sanchez-Villegas A, Basterra-Gortari FJ, et al. Prospective study of self-reported usual snacking and weight gain in a Mediterranean cohort: the SUN project. Clin Nutr. 2010;29(3):323-330.

26. Aljuraiban GS, Chan Q, Oude Griep LM et al. The impact of eating frequency and time of intake on nutrient quality and Body Mass Index: the INTERMAP Study, a Population-Based Study. J Acad Nutr Diet. 2015;115(4):528-36.e1.

27. Nădășan V, Șular F, Horvath A, Tarcea M, Ábrám Z. Particularități demografice ale participanților la o campanie de promovare a sănătății. Buletinul Academiei de Științe a Moldovei. 2013;5(41):200-205.

28. Stock C, Wille L, Krämer A. Gender-specific health behaviors of German university students predict the interest in campus health promotion. Health Promot Int. 2001;16(2):145-154.

29. Johansson $H$, Stenlund $H$, Lundström L, Weinehall L. Reorientation to more health promotion in health services - a study of barriers and possibilities from the perspective of health professionals. J Multidiscip Healthc. 2010;26(3):213-224.

30. Zainuddin R, Abdullah N, Din SZM, Yeow PHP, Loo HS. A Study of Public Health Awareness among the Elderly in an Industrially Developing Country. J Soc Sci. 2011;7(2):152-157.

31. Petróczi A, Nepusz T. Methodological considerations regarding response bias effect in substance use research: is correlation between the measured variables sufficient? Subst Abuse Treat Prev Policy. 2011;6:1. 